\title{
The Ussing Chamber System: Functioning and Determination of Intestinal Transepithelial Electrical Measurements and Intestinal Integrity in Broiler Chickens
}

\author{
R. Umaya Suganthi, P.K. Malik, G.B. Manjunatha Reddy
}

10.18805/IJAR.B-4469

\begin{abstract}
Background: The epithelial barrier integrity reflects gut health in broiler chickens and impaired intestinal barrier is associated with production losses. So, the present report was undertaken to determine the transepithelial electrical measurements and intestinal integrity of intestinal tissues in broilers from retail shops in Bangalore, India using an Ussing chamber system.

Methods: For the present study, commercial broiler chickens were purchased from registered retail meat shops, sacrificed and the intestinal tissues were collected. The transepithelial electrical voltage, short circuit current and transepithelial electrical resistance were measured in jejunum using a contemporary Ussing chamber system following methodologies as detailed in the manuscript. Result: The studied intestinal tissues exhibited transepithelial electrical movements across intestine and the integrity of intestinal tissues were maintained. The study also indicated the preservation of intestinal barrier integrity of broilers at the crucial destination of the live broiler chicken market which in turn ascertains the quality of the product offered to the customers.
\end{abstract}

Key words: Broilers, Duodenum, Intestinal integrity, Transepithelial electrical resistance, Ussing chamber

\section{INTRODUCTION}

The intestinal epithelium in broiler chickens is composed of a single layer of epithelial cells connected by intercellular junctional complexes including tight junctions, adherens junctions and desmosomes that seal the paracellular space (Thomson et al., 2019). The epithelial barrier executes the role of a selectively permeable barrier by permitting selective absorption of nutrients, water and electrolytes and as well as a protective barrier by preventing the entry of deleterious antigens, pathogenic microbes and their toxins into circulation (Groschwitz and Hogan, 2009). An intact intestinal barrier is essential for optimum health and performance of birds as impairment in intestinal barrier function is linked with intestinal and enteric bacterial diseases, frequent health problems and production losses (Lambert, 2009; Hu et al., 2013; Emami et al., 2019; Wu et al., 2019).

The equipment, Ussing chamber, named after the inventor, Hans Ussing was first developed to decipher the sodium chloride active transport mechanism in frog skin (Ussing and Zerahn 1951). Since the date of its invention, it is one of the excellent and most preferred methods to measure intestinal epithelial tissue integrity and transport of nutrients, electrolytes and drugs across epithelial tissues (Li et al. 2004). Ussing chamber can be used to record transepithelial electrical measurements such as transepithelial potential difference (PD), short circuit current (Isc) and transepithelial electrical resistance (TER). Transepithelial electrical resistance is deemed as a noninvasive method to quantify intestinal barrier integrity that reflects the opening of tight junctions between epithelial cells and paracellular permeability of intestinal mucosa (Wijtten
ICAR-National Institute of Animal Nutrition and Physiology, Bangalore-560 030, Karnataka, India.

1 ICAR-National Institute of Veterinary Epidemiology and Disease Informatics, Bangalore-560 064, Karnataka, India.

Corresponding Author: R. Umaya Suganthi, ICAR-National Institute of Animal Nutrition and Physiology, Bangalore-560 030, Karnataka, India. Email: r.umayasuganthi@gmail.com

How to cite this article: Suganthi, R.U., Malik, P.K., Reddy, G.B.M. (2021). The Ussing Chamber System: Functioning and Determination of Intestinal Transepithelial Electrical Measurements and Intestinal Integrity in Broiler Chickens. Indian Journal of Animal Research. 55(11): 1303-1307. DOI: 10.18805/IJAR.B-4469.

Submitted: 31-03-2021 Accepted: 16-06-2021 Online: 03-08-2021

et al., 2011). The impairment in epithelial barrier integrity caused by heat stress (Maseko et al., 2014), high stocking density (Goo et al., 2019) and lipopolysaccharide (Cao et al., 2018) and deoxynivalenol (Awad et al., 2019) in broilers has been established using this system.

Indian broiler industry stands as one of the most lucrative food industries in the country. Approximately $95 \%$ of chicken consumed are sold as live chickens due to the preference of consumers for live and fresh chicken (Mehta and Nambiar, 2003; Mech et al., 2021). In this perspective, the retail meat shops represent a crucial destination in broiler supply chain in the wet market before it reaches customers. The chickens sold at retail meat shops are usually from various sources ranging from rural small scale poultry units to large-scale commercial poultry units located in different geographical areas. Once the birds reach 35-42 days of 
age (market age) and an average body weight of $1.8-2.2 \mathrm{~kg}$, they are subjected to feed withdrawal, housed in cages and transported by road over a long distance to retail shops in urban areas or centralized processing plants (Sarkar et al. 2013; Jayaprakash et al., 2016). The processes of feed withdrawal, confinement and temperature fluctuations during transport may induce stress to birds (Jayaprakash et al., 2016). This in turn may affect gut health, impair intestinal integrity and lead to contamination of carcasses with intestinal microbes including zoonotic pathogens during slaughter. All these factors finally affect the quality of product and pose risk to consumer health. However, the data on intestinal integrity of broilers at this prime junction (retail meat shops) in the Indian poultry sector is not available.

Therefore, the present study was aimed to determine transepithelial electrical measurements and intestinal integrity of broilers in retail shops that are ready for sale to customers. To the best of our knowledge, in India, this is the first report to reveal the transepithelial electrical measurements and intestinal integrity in broilers using a contemporary Ussing chamber system.

\section{MATERIALS AND METHODS Chemicals}

All the chemicals used were of analytical grade, procured from Sigma Aldrich, India and Hi-media Laboratories, Mumbai.

\section{Location of the experiment}

The study was conducted at ICAR-National Institute of Animal Nutrition and Physiology, Bangalore during 2018 and 2019.

\section{The Ussing chamber system-setup}

The Ussing chamber system used for the present study consisted of a Chamber (Warner Instruments, USA) connected to a temperature-controlled water bath (Daihan Scientific), an Epithelial Voltage Clamp (amplifier) (Warner
Instruments, USA) and data acquisition and monitoring system (Power Lab equipped with Lab Chart software, AD Instruments, Australia) (Fig 1).

\section{The Ussing chamber}

The Ussing chamber is an acrylic, transparent, vertical apparatus divided into two hemi- chambers (chamber halves) that accommodates epithelial tissues mounted on a tissue insert. The upper portion of each hemi-chamber has a buffer chamber to hold experimental buffer, bathe intestinal tissues and assist electrical recordings.

\section{Electrodes}

Electrodes form the integral elements of the Ussing system that provide low resistance interface between the buffer and electronic equipment. Each hemi chamber works with two current and two voltage electrodes to establish electrical circuits. In the present study, ready to use sintered $\mathrm{Ag} / \mathrm{AgCl}$ pelleted electrodes were used as voltage electrodes and chlorided silver wires were used as current electrodes. The current electrodes were manually chlorided before every use using household bleach. Subsequently, electrodes were rinsed with distilled water to remove the bleach. After completion of each sample, silver chloride coating was removed by gently wiping with glass wool. New (unused) silver wire was cleaned with ethanol before proceeding with chloriding procedure. Agar-salt bridges were used to connect electrodes and buffer to prevent epithelium exposure to the toxic effects of $\mathrm{Ag}$ from $\mathrm{Ag}-\mathrm{AgCl}$ electrodes (Clarke, 2009). Agar bridges were prepared by heating a mixture of $3 \%$ agar with KCL solution and solidified in specialized disposable tips. Utmost care was taken to avoid the introduction of air bubbles during the preparation of agar-salt bridges to avoid disturbance in electrical recordings. The voltage electrodes were positioned near the epithelium to the extent possible to reduce the magnitude of solution series resistance while current electrodes were placed as far as possible from the

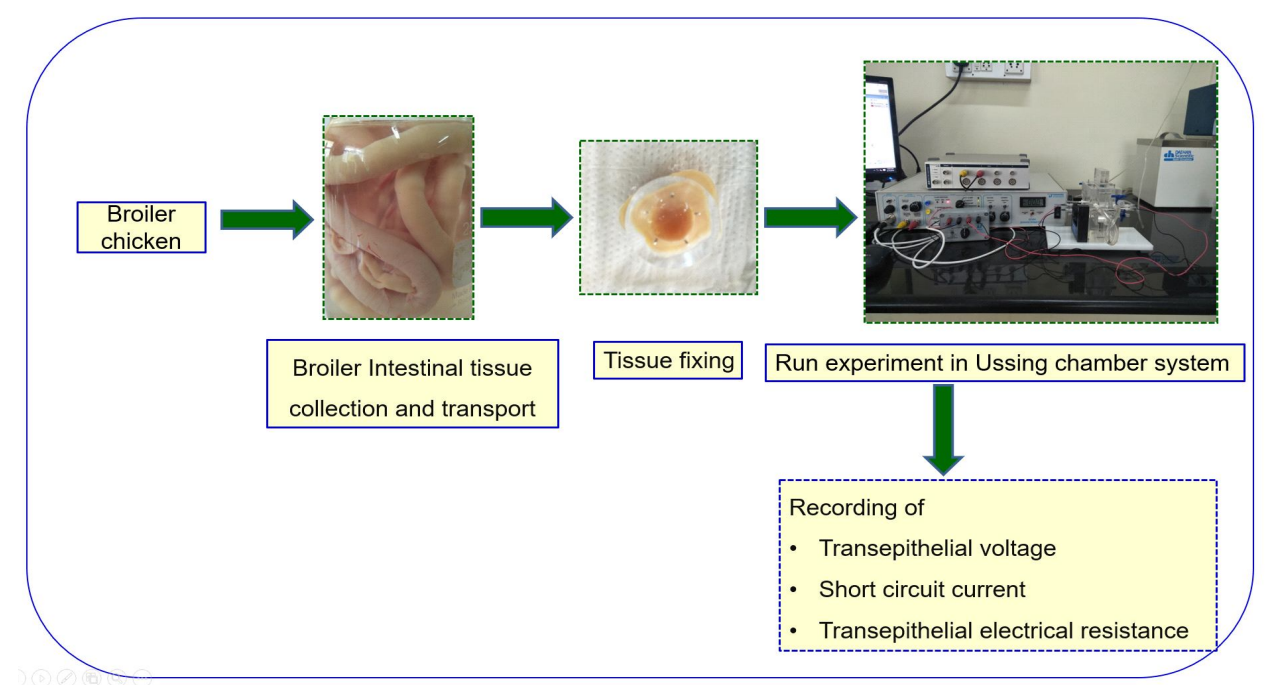

Fig 1: Recording of transepithelial electrical measurements in jejunum of broilers. 
The Ussing Chamber System: Functioning and Determination of Intestinal Transepithelial Electrical Measurements and Intestinal...

epithelium to ensure a uniform current density across the epithelium.

\section{Initial set up of chamber}

The hemi-chambers were aligned together, clamped and the voltage (V1, V2) and current electrodes (I1, I2) were connected to the hemi chambers and the voltage clamp. Subsequently, Krebs-Ringer bicarbonate buffer (125.4 mM $\mathrm{NaCl}, 5.4 \mathrm{mM} \mathrm{KCl}, 1.2 \mathrm{mM} \mathrm{CaCl}_{2} .2 \mathrm{H}_{2} \mathrm{O}, 21.0 \mathrm{mM} \mathrm{NaHCO}_{3}$, $0.3 \mathrm{mM} \mathrm{Na}_{2} \mathrm{HPO}_{4}$ and $1.2 \mathrm{mM} \mathrm{NaH}_{2} \mathrm{PO}_{4}$ ) was gently added to each buffer chambers and water supply was switched on.

\section{Processing and mounting of tissues}

The animal experiment protocols followed in the present experiment were approved by the Institutional animal ethics committee of ICAR-NIANP. For the present study, apparently healthy commercial broiler chickens $(n=18)$ weighing 1.8 to $2.2 \mathrm{~kg}$ (includes both male and female birds) were purchased from registered retail meat shops by simple random sampling method. The birds were sacrificed at the Experimental Livestock Unit of ICAR-NIANP. Immediately, the abdominal cavity was opened, whole intestinal tracts were collected, rinsed with ice-cold saline $(0.9 \% \mathrm{w} / \mathrm{v})$ and transported to laboratory within 5 minutes of slaughter in ice-cold oxygenated ( $95 \%$ oxygen $/ 5 \%$ carbondioxide) KrebsHenseleit buffer Krebs-Henseleit buffer (Thomson et al., 2019) to avoid ischemia during transport to the laboratory.

The small intestine comprises of three segments: duodenum (from the outlet of gizzard to the end of the pancreatic loop), jejunum (from pancreatic loop to Meckel's diverticulum) and ileum (from Meckel's diverticulum to cecal junction) (Wu et al., 2013). From the samples brought to the laboratory, small portions of jejunal tissues from whole tracts were dissected out and flushed with ice-cold oxygenated transport Kreb's buffer to remove luminal contents. The tissues were cut open, placed in glucosecontaining Krebs-Henseleit buffer on ice, aerated continuously with carbogen gas and the serosal and muscular layers were stripped off. Subsequently, tissues were fixed on to tissue insert having a round aperture. Since the diameter of broiler intestinal tissues is more compared to laboratory animals, tissue insert with an aperture size of $1.2 \mathrm{~cm}^{2}$ surface area were used to hold the tissues. The inserts holding the intestinal epithelium were placed vertically such that the apical side and basolateral sides of the epithelial membrane separate the hemi-chambers. A known volume of fresh prewarmed buffer $(8-9 \mathrm{ml})$ was added to each buffer chamber. Additionally, $10 \mathrm{mM}$ glucose and $10 \mathrm{mM}$ mannitol were added to serosal and mucosal buffer respectively to provide energy and maintain osmotic balance across the mucosa. The buffer and intestinal tissues were maintained at $38-39^{\circ} \mathrm{C}$ by the water jacket. The carbogen gas was supplied using a gas lift mechanism to provide oxygen to tissues and maintain buffer at physiological $\mathrm{pH}$ of 7.4 .

Following tissue mounting, the setup was allowed to stabilize for 10-30 minutes till a stable baseline was obtained.
The basal transepithelial electrical voltage and short circuit current were measured continuously and recorded by the Data acquisition system. Short-circuit current (Isc) refers to the charge flow per time when the tissue is short-circuited (i.e. transepithelial voltage is clamped to $0 \mathrm{mV}$ ) ( $\mathrm{Li}$ et al. 2004). To measure transepithelial electrical resistance, the system was pulsed with $3 \mathrm{mV}$ periodically in voltage-clamp mode and the resulting change in Isc was recorded. TER was expressed as $\Omega$ (ohms) $/ \mathrm{cm}^{2}$.

\section{RESULTS AND DISCUSSION}

The intestinal epithelial barrier functions as a dynamic physical barrier and as well as an interface between the body interior and exterior (Groschwitz and Hogan, 2009). The impairment or loss of integrity of this integrated barrier increases luminal antigen permeability, systemic diseases and hampers broiler production (Moeser et al., 2007). The present report describes the methodology to measure intestinal integrity of retail shop sourced broiler intestinal samples using Ussing system ex vivo. Ussing chamber has been a method of choice to study intestinal integrity of mice, human tissues (Thomson et al,. 2019), laying hens (Awad et al., 2004), pigs (Pearce et al., 2013), ruminants (Greco et al., 2018) and, in intestinal cells in vitro (Thomson et al., 2019). In Ussing chamber, the isolated intestinal tissues that still retain the morphological and the physiological features of intestine are used. So, it provides an excellent opportunity to decipher epithelial barrier phenomena (Rozehnal et al. 2012). However, to the best of our knowledge, data on intestinal integrity of broilers at retail shops ready for slaughter to consumers is limited (Table 1).

To assess the intestinal integrity using Ussing chamber, jejunum was selected due to its vital role in absorption of nutrients. The PD and Isc recordings observed in the present study were $1.54 \pm 0.50\left(\mathrm{mV} / \mathrm{cm}^{2}\right)$ and $7.70 \pm 2.12\left(\mu \mathrm{A} / \mathrm{cm}^{2}\right)$ respectively and were slightly different from that reported by Ruhnke et al. (2015) in broilers raised under deep litter system. The asymmetric distribution of ion channels on the apical (mucosal side) and basolateral membranes of epithelial cells favors transport of ions across epithelial layer, thus generating a potential difference across the epithelial layer (Clarke, 2009). The electrical current across the epithelium results mainly from the absorption of $\mathrm{Na}^{+}$and secretion of $\mathrm{Cl}_{2}$ (Awad et al., 2004) and the possible reason

Table 1: Transepithelial voltage, short circuit current and transepithelial electrical resistance across jejunum in broiler chickens using an Ussing chamber system.

\begin{tabular}{lc}
\hline Parameter & $\begin{array}{c}\text { Recordings in broiler } \\
\text { chickens }(\mathrm{n}=18)\end{array}$ \\
\hline Transepithelial voltage (TEV), $\mathrm{mV} / \mathrm{cm}^{2}$ & $1.54 \pm 0.50$ \\
Short circuit current (Isc), $\mu \mathrm{AA} / \mathrm{cm}^{2}$ & $7.70 \pm 2.12$ \\
Trans epithelial electrical resistance & $471 \pm 34$ \\
(TER), $\Omega / \mathrm{cm}^{2}$ &
\end{tabular}

Values represent Mean \pm SE. 
The Ussing Chamber System: Functioning and Determination of Intestinal Transepithelial Electrical Measurements and Intestinal...

for the difference in PD and Isc indicates altered sodium transport (Tahir et al., 2019) due to closure of ion channels (Awad et al., 2014).

A multitude of factors, such as time of first feed availability (Obun and Osaguana, 2013), exposure to bacterial pathogens (Pearce et al. 2013), stress (Moeser et al., 2007), intestinal inflammation (Thomson et al., 2019) and mycotoxins (Awad et al., 2004) influence intestinal integrity. In the present study, a TER of $471 \pm 34\left(\Omega / \mathrm{cm}^{2}\right)$ has been recorded. Recently, Goo et al. (2019) have reported a basal TER value of $345 \Omega / \mathrm{cm}^{2}$ in broilers at 28 days of age and previously Shakeri et al. (2018) have recorded a TER of $149 \Omega / \mathrm{cm}^{2}$ in 42 day old chickens raised under a deep litter system. The TER obtained in the present study demonstrated that the intestinal integrity of the epithelial layer is maintained and not jeoparadized in the studied broiler chickens. Any loss of intestinal integrity leads to intestinal hyperpermeability (Otani and Coopersmith, 2019), entry of pathogenic microbes and metabolites into circulation, contamination of meat with microbes, including drug-resistant bacteria during slaughter (Davis et al., 2018). Hence the intact epithelial barrier observed in these birds at the crucial destination of the broiler supply chain indicates the quality of the product to the customers.

\section{CONCLUSION}

The Ussing chamber system is a specialized instrument to assess the intestinal integrity in different species and cell culture models. The present study describes the complete assembly and working of Ussing system for evaluation of intestinal integrity of broilers. The results of the present study revealed that the broiler chickens at retail meat shops in Bangalore exhibited transepithelial ion movements in intestine and the integrity of intestinal tissues were maintained. In the current scenario that emphasizes the importance of maintaining gut health and intestinal integrity in poultry production, the present study indicates the quality of the birds which would be boon for the Indian poultry industry. However similar investigations are needed in different parts of the country/world. The utilization of Ussing chamber can also be further extended to study the transport of nutrients, drugs and correlation of intestinal integrity with gut microbiome, intestinal and systemic diseases and broiler productivity.

\section{ACKNOWLEDGEMENT}

The authors thank Director, ICAR-NIANP for providing all the required facilities to carry out the work and prepare the manuscript.

\section{REFERENCES}

Awad, W.A., Bohm, J., Razzazi-Fazeli, E., Hulan, H.W. and Zentek, J. (2004). Effects of deoxynivalenol on general performance and electrophysiological properties of intestinal mucosa of broiler chickens. Poultry Science. 83: 1964-1972.
Awad, W.A., Hess, C., Khayal, B., Aschenbach, J.R. and Hess, M. (2014). In vitro exposure to Escherichia coli decreases ion conductance in the jejunal epithelium of broiler chickens. Plos One. 9: 92156. doi: 10.1371/journal. pone.0092156.

Awad, W.A., Ruhnau, D., Hess, C., Doupovec, B., Schatzmayr, D. and Michael, H. (2019). Feeding of deoxynivalenol increases the intestinal paracellular permeability of broiler chickens. Archives of Toxicology. 93: 2057-2064.

Cao, S., Zhang, Q., Wang, C. and Wu, H. (2018). LPS challenge increased intestinal permeability disrupted mitochondrial function and triggered mitophagy of piglets. Innate Immunity. 24: 224-230.

Clarke, L.L. (2009). A guide to Ussing chamber studies of mouse intestine. American Journal of Physiology-Gastrointestinal and Liver Physiology. 296: 1151-1166.

Davis, G.S., Waits, K., Nordstrom, L., Grande, H., Weaver, B., Papp, K., Horwinski, J., Koch, B., Hungate, Ab.A., Liu, C.M. and Price, L.B. (2018). Antibiotic-resistant Escherichia coli from retail poultry meat with different antibiotic use claims. BMC Microbiology. 18: 1-7.

Emami, N.K., Calik, A., White, M.B., Young, M. and Dalloul, R.A. (2019). Necrotic enteritis in broiler chickens: The role of tight junctions and mucosal immune responses in alleviating the effect of the disease. Microorganisms. 7: 231. doi: $10.3390 /$ microorganisms 7080231 .

Goo, D., Kim, J.H., Choi, H.S., Park, G.H., Han, G.P. and Kil, D.Y. (2019). Effect of stocking density and sex on growth performance, meat quality and intestinal barrier function in broiler chickens. Poultry Science. 98: 1153-160.

Greco, G., Hagen, F., Meibner, S., Shen., Z, Lu., Z, Amasheh, S. and Aschenbach, A.R. (2018). Effect of individual SCFA on the epithelial barrier of sheep rumen under physiological and acidotic luminal $\mathrm{pH}$ conditions. Journal of Animal Science. 96: 126-142.

Groschwitz, K.R. and Hogan, S.P. (2009). Intestinal barrier function: Molecular regulation and disease pathogenesis. Journal of Allergy and Clinical Immunology. 124: 3-22.

Hu, C.H., Xiao, K., Luan, Z.S. and Song, J. (2013). Early weaning increases intestinal permeability, alters expression of cytokine and tight junction proteins and activates mitogenactivated protein kinases in pigs. Animal Science. 91: 1094-1101.

Jayaprakash, J., Sathiyabarathi, M., Robert, M.A. and Tamilmani, T. (2016) Transportation stress in broiler chicken. International Journal of Science. 5: 806-809.

Lambert, G.P. (2009). Stress-induced gastrointestinal barrier dysfunction and its inflammatory effects. Journal of Animal Science. 87: 101-108.

Li, H., Sheppard, D.N., Hug, M.J. (2004). Transepithelial electrical measurements with the Ussing chamber. Journal of Cystic Fibrosis. 3: 123-126.

Maseko, T., Dunshea, F.R., Howel, L.K., Chorivera, H., Furness, L.R.B.J. and Neg, K. (2014). Selenium-enriched Agaricus bisporus mushroom protects against increase in gut permeability ex vivo and up-regulates glutathione peroxidase 1 and 2 in hyperthermally-induced oxidative stress in rats. Nutrients. 6: 2478-2492. 
The Ussing Chamber System: Functioning and Determination of Intestinal Transepithelial Electrical Measurements and Intestinal...

Mech, A., Suganthi, U., Rao, S.B.N., Sejian, V., Soren, M., David, C., Awachat, V. and Kadakol, V. (2021). Effect of dietary supplementation of linseed oil and nat ural antioxidants on production performance, fatty acid profile and meat lipid per oxidation in broilers. Asian Journal of Dairy and Food Research. 40: 62-68.

Mehta, R. and Nambiar, R.G. (2003). The Poultry Industry in India. In: Poultry in the $21^{\text {st }}$ Century. Avian iinfluenza and Beyond. In: Proceedings of the International Poultry Conference, held 5-7 November 2007, Bangkok, Thailand. [Edited by O. Thieme and D. Pilling]. FAO Animal Production and Health Proceedings, No. 9. Rome, 149-209.

Moeser, A.J., Klok, C.V., Ryan, K.A., Wooten, J.G., Little, D., Cook, V.L. and Blikslager, A.T. (2007). Stress signaling pathways activated by weaning mediate intestinal dysfunction in the pig. American Journal of Physiology-Gastrointestinal and Liver Physiology. 292: 173-181.

Obun, C.O. and Osaguona, P.O. (2013). Influence of post-hatch starvation on broiler chick's productivity. IOSR Journal of Agriculture and Veterinary Science. 3: 5-8.

Otani, S. and Coopersmith, C.M. (2019). Gut integrity in critical illness. Journal of Intensive Care. 7: 17. Doi:10.1186/ s40560-019-0372-6.

Pearce, S.C., Mani, V., Boddicker, R.L., Johnson, J.S., Weber, T.E., Ross, J.W., Rhoads, R.P., Baumgard, L.H. and Gabler, N.K. (2013). Heat stress reduces intestinal barrier integrity and favors intestinal glucose transport in growing pigs. Plos One. 8: 8. Doi:10.1371/journal.pone.0070215.

Rozehnal, V., Nakai, D., Hoepner, U., Fischer, T., Kamiyama, E., Takahashi, M., Yasuda, S. and Mueller, J. (2012). Human small intestinal and colonic tissue mounted in the Ussing chamber as a tool for characterizing the intestinal absorption of drugs. European Journal of Pharmaceutical Sciences. 46: 367-373.

Ruhnke, I., De Biasio, J.V., Suchodolski, J.S., Newman, S.J., Musch, M.W. and Steiner, J.M. (2015). Evaluation of endoscopically obtained duodenal biopsy samples from cats and dogs in an adapter-modified Ussing chamber. Journal of Veterinary Science. 15: 297-307.
Sarkar, P., Ghosh, S., Batabyal, S. and Chatterjee, S. (2013). Biochemical stress responses of broiler chickens during transport. Indian Journal of Animal Research. 47: 29-34.

Shakeri, M., Cottrell, J.J., Wilkinson, S., Ringuet, M., Furness, J.B. and Dunshea, F.R. (2018). Betaine and antioxidants improve growth performance, breast muscle development and ameliorate thermoregulatory responses to cyclic heat exposure in broiler chickens. Animals. 8: 162. doi: 10.3390 /ani8100162.

Tahir, S.K., Yousaf, M.S., Ahmad, S. et al. (2019). Effects of chromium-loaded chitosan nanoparticles on the intestinal electrophysiological indices and glucose transporters in broilers. Animals. 9: 819. Doi:10.3390/ani9100819.

Thomson, A., Smart, K. and Somerville, M.S. et al. (2019). The Ussing chamber system for measuring intestinal permeability in health and disease. BMC Gastroenterology. 19: 98. Doi:10.1186/s12876-019-1002-4.

Ussing, H.H. and Zerahn, K. (1951). Active transport of sodium as the source of electric current in the short-circuited isolated frog skin. Acta Physiologica Scandinavica. 23: 110-127.

Wijtten, P.J., Meulen, J. and Verstegen, M.W. (2011). Intestinal barrier function and absorption in pigs after weaning: A review. British Journal of Nutrition. 105: 967-981.

Wu, Q.J., Jiao, Z.H., Liu, S.W., Li, D.D., Ma, W.F., Wang, Y.Q., Wang, Y. and Wu, X.H. (2019). Effect of glutamine on the intestinal function and health of broilers challenged with Salmonella pullorum. Indian Journal of Animal Research. 53: 1210-1216.

Wu, R.Y., Pasyk, M., Wang, B., Forsythe, P. and Bienenstock, S.J. (2013). Spatiotemporal maps reveal regional differences in the effects on gut motility for Lactobacillus reuteri and rhamnosus strains. Neurogastroenterology and Motility. 25: 205-214. 